\title{
READERS
}

Journal of Management Info (JMI)

ISSN:2313-3376

www.readersinsight.net/jmi

MA

\section{The study of relationship between internet addiction and aggression among teenagers}

\author{
Bibi Asma Khatoon ${ }^{1}$, Andleeb Akhtar², Raja Ahmed Jamil ${ }^{3 *}$, Assad Rahman ${ }^{4}$ \\ ${ }^{1}$ Department of Psychology, University of Haripur \\ ${ }^{2,3}$ Department of Management Sciences, University of Haripur \\ ${ }^{4}$ Faculty of Management Sciences, Riphah International University \\ * Corresponding author: raja.ahmed@uoh.edu.pk
}

\begin{abstract}
This study was designed to investigate the relationship between internet addiction and aggression among teenagers and to establish the psychometric properties of the scales. A standardized questionnaire was used to collect information about level of internet addiction and aggression among teenagers. To establish the psychometric properties, sample ( $n=200$, having age 15-19 years) was selected from different schools and colleges of Haripur city. The results of research showed that the predictor variable; internet addiction $(\beta=.88)$, had a very high significant positive effect on outcome variable; aggression, with the level of significance $p \leq .000$. The $t$-Test analysis showed significant differences between males and females in both variables.
\end{abstract}

\section{ARTICLE INFORMATION}

Received: 25 November 2016 Revised: 25 December 2016 Accepted: 25 December 2016

DOI:

http://dx.doi.org//10.31580/jmi.v12i1.61

\section{Background}

Technology is changing continuously with the pacing of the world. These growing changes bring social and economical penalties on different aspects of our routine life. Some of the changes in the last decade were difficult to cope with. In the future, these changes will happen even faster, with least time to prepare. Thus "Positive and Negative Changes" are the two aspects of this changing technology for the users (Rajani \& Chandio, 2004).

The prevalence of internet use has increased markedly worldwide in these recent years with the current estimation of 500 million internet users. Along with all benefits the internet brings, problems due to excessive use are also becoming apparent. Results of heavy internet usage may include educational problems, difficulties in work and family responsibilities, disturbance of relationships, economic problems and social loneliness (as cited in Widyanto \& Mcmurran, 2004). The people should not use the internet to the degree that they experience such evils that give rise to the issue of whether or not the internet may be addictive. The idea of addiction is not simple to describe, but main theme of it is reliance on a substance or activity. Dependence is marked by toleration, withdrawal, craving, intemperance and loss of control. Although initially associated with substance use only, there is growing recognition of behavioral addiction such as betting, overeating and work out (as cited in Widyanto \& Mcmurran, 2004). Behavioral addictions are behaviors that relate to the use of machines, such as playing video games, using computers and playing amusement machines throughout the past few decades, the internet has become gradually more important in youths' lives (as cited in Widyanto \& Mcmurran, 2004).

Among all behavioral addictive traits, the internet stands out for its importance to the future and its promise of probably delivering harmful results to millions as ease of access to the internet rises worldwide (as cited in Tumanov, 2011). Teen agers are very important part of the society and it is the responsibility of society and its caregivers to educate them about what is right and what is wrong. Nowadays, few habits are really changing their attitudes negatively apart from many other factors. One of them is internet addiction which remains as a controversial topic for more than a decade after it was described first. Internet addiction is the term employed to those who expend extreme amounts of time online at the cost of causing harm to other aspects of their lives. The Child Net International (2006) defines internet addiction as a fanatical behavior that takes the form of special activities and might comprise any or all of the following:

(1) Money through spontaneously gambling online, trading online and chipping in online auctions.

(2) Relationships, by spending needless amounts of time starting and preserving online friendships in chat rooms, which usually substitute real life friends and family.

(3) Information exploring, as in neurotic web surfing of databases.

(4) Gaming as in obsessive computer game playing, as well as multiuser games.

(5) Sex, addiction to adult chat rooms, cybersex or pornography on the internet (as cited in Lucy, 2011).

The notion of internet addiction refers to the extreme use of internet which in reverse causes a variety of problems in individual, social and professional aspects (Sahin, 2011). Kandell determined in 1998 internet addiction as "a psychological dependence on the internet, regardless of the type of activity once logged on" (as cited in Chou, Condron, Belland, 2005). Internet addiction is a psychological necessity of the internet which is described as investment of huge amount of resources on internet associated actions; unfriendly thoughts while off-line, a growing lenience to the results of being online and renunciation of the challenging activities (Kandell, 1998). Basically, Lin in 2007 mentioned that internet has become a vital part 
of teen agers' lives as it offers access to the world (as cited in Lucy, 2011).

Another element which is troubling daily routine lives of teenagers is aggression. Increase of violence in the world recommends scientists to explore the reasons or the factors accountable for the negative behavior in the human beings, particularly in children and teenagers. The focus is to identify these reasons and to prevent the development of aggressive behavior in the children and adolescents.

There may be several other definitions for aggression such as, according to Buss it is a type of reaction that delivers toxic stimuli to other organisms (as cited in Geen \& Donnerstein, 1998). According to Berkowitz (1968) people use this term "aggression" to explicate any behavior which objective is to damage other people or things. The term "aggression" may be defined as any act that can cause suffering or antipathy

According to Moyer aggression is a worldwide phenomenon and it is of diverse kinds. Almost all animal species depicts violent acts, for instance territorial aggressive behavior, predatory aggression and maternal aggressive acts (as cited in Hayes, 1994). Maguire and Pastore mentioned in 1998 that violence is one of the most dominant and negative behaviors that youngsters face at present, because they are at particular danger of being either the prey or the committer of an act of hostility (as cited in Orpinas, 2001).

Violence is of diverse types and also changes with respect to culture. The acts believed as violent in one cultural context may not be considered as violent in other societies. Human beings also demonstrate different kinds of violent behaviors. Most widespread of them is aggression. In other words, it could be said that aggression is the vital element of violent behavior. It is also uttered in variety of ways, which may include physical aggression, verbal aggression, relational aggression etc, (Mattson, 2003). Aggressive acts not only influence the victims but cause problems in violent persons' life and trouble the whole system of humanity (Ali, 2008).

Internet addiction and aggression are two most important issues of our society in current time. From past so many years different researcher's attempted to reveal facts and findings about aggression and internet addiction. Many experts tried to find out causes, effects, symptoms and different aspects of these variables and how they can be problematic for human beings. Different studies regarding these two variables have been conducted.

According to Scherer (1997) mostly internet dependents reported that internet use had interfered with their educational life, occupational performance and public lives and it had negative effects on their daily routines. Scherer (1997) established that males were more internet dependents than females. Young and Rodgers (1998) found that depression is significantly correlated with problematic internet use. According to Young (1998) internet addicts reported problematic use of internet caused personal, family and occupational problems and its major outcome was time distortion and for students it caused educational problems. Young (1998) established that internet addicts mostly used internet for two ways communication functions and non addicts mostly used it for information gathering functions while according to Lin and Tsai (1999) Taiwan high schools students reported that excessive use of internet had positive influence on their peer relations but it had negative effects on their academic life and daily routines. Morahan, Martin and Schumacker (2000) found that pathological use of internet is positively correlated with loneliness.

Jenaro, Flores, Gomez-Vela and Caballo (2007) reported significant positive correlation between extreme use of internet and negative emotions (such as anxiety, depression and fatigue). Liu and Kuo (2007) found that social anxiety due to problematic interpersonal relationships is positively correlated with internet addiction whereas Kim, Park, Kim, Jung, Lim and Kim (2010) obtained that internet addiction is linked with a variety of problems for example, inappropriate nutritional behavior and poor diet quality, which could result in underdeveloped growth.

According to Esen and Gundogdu (2010) peer interaction, parental and teacher support has great influence on internet addiction. Lower peer pressure and more parental and teacher's support decreases the internet addiction and boys have more internet addiction than girls. Frangos and Sotiropoulos (2011) found that the problematic use of internet was correlated with other possible addictive personal habits such as drinking alcohol, smoking, drinking coffee and taking drugs. According to Anderson and Bushman (2002) frequent vicious game playing provides practice, learning and reinforcement to hostility, which then increases the aggression of personality. Chiu, Lee and Huang (2004) found that video game addiction is positively correlated with hostility and negatively associated with academic achievement and social skills. Negative video gaming effects are more widespread in males than females (Ko, Yen, Chen, Chen \& Yen, 2005; Ko, Liu, Hsiao, Yen, Yang, Lin, Yen \& Chen, 2009). According to Yang (2005) extreme internet addicts scored considerably higher on hostility, anxiety and depression and they inclined to be lonelier.

Takahira, Ando and Sakamoto (2008) found that use of the internet causes depression, aggression and preference for internet communication but it had no effect on loneliness.

Barkoviak (2009) discovered that internet addiction can lead to attention deficit hyperactivity disorder (ADHD), hostility and social phobia. Munteanu, et al., (2009) found that internet addicts have to face negative outcomes like depression, aggressive behavior and generalized anxiety than those who are not suffering from this disorder.

Mehroof and Griffiths (2010) detected that five traits (neuroticism, sensation seeking, trait anxiety, state anxiety and aggression) displayed significant associations with online gaming addiction. Alavi, Alaghemandan, Maracy, Jannatifard, Eslami and Ferdosi (2010) studied that internet addiction causes few mental problems such as, anxiety, depression, aggression and job and educational dissatisfaction.

Alaviet al., (2011) discovered relationship between internet addiction and psychiatric symptoms such as somatization, sensitivity, depression, anxiety, aggression, phobias and psychosis with omission of paranoia and male students tend to use internet more frequently than females. Feng, Ho and Song (2011) found that online aggression and real world aggression were moderately correlated. Students with a strong tendency to display aggression in real life are likely to show aggressive behavior on the internet and on the other hand students, who were aggressive toward others online, were also likely to exhibit aggressive behavior in real life.

\section{Methods}

The present study has the following objectives:

\section{Objectives}

i) To establish the psychometric properties of the instruments in our culture.

ii) To study the relationship between internet addiction and aggression.

iii) To study the gender differences among internet addicts.

iv) To study aggression among males and females.

\section{Variables defined}

Internet addiction. Internet addiction is an individual's inability to control his/her uses of the internet, which ultimately causes mental, societal, school and work difficulties in a person's life (Young, 1998 as cited in Regina, et al., 2008). It is operationalized as the scores on Kimberley young's internet addiction questionnaire. On this scale scoring high is characterized as severe level of internet addiction.

\section{Aggression}

Buss and Perry (1992) defined "aggression in terms of its four sub traits such as physical aggression, verbal aggression, anger and hostility. Physical and verbal aggression which involves hurting or harming others represents the instrumental or motor component of behavior. Anger, which involves physiological arousal and preparation for aggression, represents the emotional or affective component of the behavior. Hostility, which consists of feeling of ill 
will and injustice, represents the cognitive component of behavior. It is operationalized as the scores on Buss-Perry Aggression scale. High scores on this scale show higher level of aggression and low scores on the scale shows lower level of aggression".

\section{Teen agers}

Teen ager is considered to be an individual between the ages of 13 and 19 inclusive (Erikson, 1950).

\section{Instruments used}

The internet addiction questionnaire. Internet addiction questionnaire used to measure internet addiction in teenagers was developed by Young $(1996,1998)$. This questionnaire has 20 items and it measures mild, moderate and severe levels of internet Addiction. The items are rated on six point rating scale (Likert scale) ranging from 0 (Does not apply) to 5 (Always). Therefore, the minimum score on scale is 20 and the maximum score is 100 . It is widely used scale dealing with our general feeling about excessive internet use. Scores below 49 were considered to be mild and above 79 were considered to be severe and scores between these two levels were considered to be moderate.

Buss-Perry aggression scale. Aggression questionnaire used to measure aggression in adolescents was developed by Buss and Perry (1992). The questionnaire is consisted of 29 items and comprised of four sub scales which are as follows;

a) Physical aggression. It consist items from 1 to 9 .

b) Verbal aggression. It is comprised of items from 10 to 14 .

c) Anger. It consist items from 15 to 21

d) Hostility. It is comprised of items from 22 to 29.

It is a five point rating scale. The scale has been assigned weightages as 1 (least), 2 (mild), 3 (average), 4 (moderate), 5 (greatest). The score for each subscale is the sum of the rating for its items. The total score of aggression is the sum of subscales. The maximum score possible on aggression questionnaire is 145 and possible minimum score is 29. The items no. 7 and 18 are the reverse items and scored reversely.

\section{Research Design}

The present study is an exploratory study consisting of the two phases: in Phase 1, pre-testing of the scale was done while in Phase 2, the main study was conducted.

The instruments, which used in both studies were, Internet addiction questionnaire and Buss-Perry aggression scale. Both the studies were conducted in the city of Haripur. In the first phase of the study the applicability and comprehension of the scales was tested and the second phase comprised the main study.

\section{Pre-testing of the scale}

\section{Objectives of the study}

i) To test the comprehension level of scale

ii) To check the applicability of the scale in our culture

\section{Sample}

80 teen agers were taken from different settings (schools, colleges and through door to door contact from the area of Khalabat Town Ship, Haripur) and the age range was from 15 to 19 years and participants were from both genders; male and female.

\section{Instruments}

The instruments that were used in the pre testing were Internet addiction questionnaire and Buss-Perry aggression scale. Internet addiction questionnaire has 20 items measuring internet addiction at 6 point rating scale. Aggression questionnaire has 29 items measuring aggression level at 5 point rating scale and it has 2 reverse items. An opinion questionnaire was attached in the end of scales to get the response regarding the concept of internet addiction and aggression in our culture and assessing the comprehension level of the scale and the difficult items, if any.

\section{Procedure}

In the first phase the pre testing of the scales was carried out. An initial study was conducted to test the comprehension level and application of the instruments in our culture. The instruments that were used in the study were Internet addiction questionnaire and Buss-Perry aggression scale. For this purpose the scales were administered on 80 teen agers in different settings. The participants were given instructions and guidance.

\section{Results}

The participants filled the questionnaires without any difficulty. It was easy for them to read the questionnaires and response appropriately. The subjects filled the questionnaires without any difficulty and with ease and good understanding. The opinion questionnaire attached at the end showed no negative responses. The Alpha Coefficient Reliability of Internet Addiction Questionnaire was $.89(\mathrm{~N}=80)$ and Alpha Coefficient Reliability of Buss-Perry Aggression Scale was .93 $(\mathrm{N}=80)$. Thus the study confirmed the applicability of the scales.

Phase II Is elaborated as follows.

\section{Main study}

\section{Objectives}

The present study has following objectives:

i) To study the relationship between internet addiction and aggression among teen agers.

ii) To study the gender differences among internet addicts.

iii) To study aggression in males and females.

\section{Hypotheses}

H1: There is positive relationship between internet addiction and aggression.

H2: Internet addiction predicts aggression positively.

H3: Males are more internet addicts than females

H4: Males are more aggressive than females.

\section{Sample}

The sample consisted of 200 participants. All of them were chosen from different schools and colleges of Haripur city. The age of the participants ranged from 15 years to 19 years. Youngsters were selected through convenient sampling and male and female both were included.

\section{Instruments}

The instruments that were used in the main study were Internet addiction questionnaire and Buss-Perry aggression scale. Internet addiction questionnaire has 20 items measuring internet addiction at 6 point rating scale. Aggression questionnaire has 29 items measuring aggression level at 5 point rating scale and it has 2 reverse items.

\section{Procedure}

The second phase comprising the main study was conducted on the convenient sample that consisted of 200 subjects chosen from different locations. Teen agers were contacted at different schools and colleges and different locations of Haripur city.

Names of these institutes are, The Progressive International Academy Khalabat Town Ship, The Educators Haripur, Government Girls Degree College Khalabat Town Ship and Government Degree College for Boys Khalabat Town Ship.

Prior permission was taken from principals of those institutes. The participants were told about the purpose of the research and their willingness for the participation was acquired. They were ensured that their provided information would be confidential.

The internet addiction questionnaire and Buss and Perry aggression scale were administered individually to the students. Students were 
approached in classrooms and school/college grounds and even data was collected from youngsters through personal approach or by door to door contact. Before administering those scales, researcher provided instructions to subjects. And when they completed, researcher collected those questionnaires back. The data was put to analysis in SPSS and alpha reliability, correlation; linear regression analysis and t-Test of data were calculated.

\section{Results}

The data was subjected to various kinds of statistical analysis to meet the objectives of present study. To test the psychometric properties of scales, the Alpha Reliability Coefficient and Inter-Item Correlationwas used. The t-analysis was performed to study thegender differences on the Internet Addiction Questionnaire and Buss-Perry Aggression Scale (and its sub scales).The Pearson Correlation was performed to determine the relationship between internet addiction and aggression. The Linear Regression Analysis was performed to examine the effects of internet addiction on the level of aggression. Results of data analyzed are in form of tables given below.

Table 1: Descriptive Statistics and Cronbach Alpha ( $N=200)$

\begin{tabular}{lllllll}
\hline Variable & $\begin{array}{l}\text { No of } \\
\text { items }\end{array}$ & SD & Mean & Min & Max & Alpha \\
\hline Internet & 20 & 17.17 & 73.26 & 12 & 133 & .90 \\
Addiction & 29 & 21.05 & 106.55 & 41 & 137 & .94 \\
Aggression & 29 & 6.86 & 32.50 & 14 & 43 & .83 \\
$\begin{array}{l}\text { Physical } \\
\text { Aggression }\end{array}$ & 9 & & & & & \\
Verbal & 5 & 3.98 & 18.18 & 7 & 25 & .72 \\
Aggression & 5 & 5.22 & 25.41 & 10 & 33 & .74 \\
Anger & 7 & 6.96 & 29.87 & 8 & 40 & .85 \\
\hline Hostility & 8 & & & & & \\
\hline
\end{tabular}

Table 1 shows the descriptive statistics all the study variables. The reliability scores have been determined by computing Cronbach's alpha values for the Internet Addiction Questionnaire and Buss-Perry Aggression Scale. For the Aggression sub scales reliability ranged from .72 to .85 . The alpha reliability coefficient determined for internet addiction scale is .90 and for aggression scale the estimated reliability coefficient is .94. The alpha reliability coefficients indicated that all scales are internally consistent and reliable measures for the present study.

Table 2: Pearson Correlation $(\mathrm{N}=200)$

\begin{tabular}{lllllll}
\multicolumn{7}{l}{ Table 2: } \\
\hline Variable & IA & Agg & PA & VA & Ang & H \\
\hline IA & & & & & & \\
Agg & $.88^{* *}$ & & & & & \\
PA & $.83^{* *}$ & $.92^{* *}$ & & & & \\
VA & $.70^{* *}$ & $.84^{* *}$ & $.71^{* *}$ & & & \\
Ang & $.79^{* *}$ & $.90^{* *}$ & $.77^{* *}$ & $.69^{* *}$ & & \\
H & $.84^{* *}$ & $.94^{* *}$ & $.81^{* *}$ & $.76^{* *}$ & $.811^{*}$ & \\
\hline
\end{tabular}

${ }^{*}$ Correlation is significant at the 0.01 level $(2$ tailed $)$
IA=Internet Addiction, Agg=Aggression, PA=Physical Aggression, VA=Verbal Aggression, Ang=Anger, $\mathrm{H}=$ Hostility

Table 2 shows the Pearson correlation coefficient determined for Internet Addiction Questionnaire and Buss-Perry Aggression Scale along with its sub scales. The correlation values for all study variables are ranging from .69 to .94 . As clear from the table that all values carry significant level $\mathrm{p} \leq 0.01$ which means that all study variables have high significant correlation.

Table 3: Linear Regression Analysis Showing the Predicting Relationship between Internet Addiction Questionnaire and Buss-Perry Aggression Scale $(\mathrm{N}=200)$

\begin{tabular}{llll} 
Aggression Scale $(\mathrm{N}=200)$ & & & \\
\hline Construct & B & SEB & $\boldsymbol{\beta}$ \\
\hline Constant & 27.11 & 3.085 & .88 \\
Internet Addiction & 1.083 & .041 & \\
\hline
\end{tabular}

$\mathrm{R}=.88, \mathrm{R}^{2}=.78, \Delta \mathrm{R}^{2}=.78, \mathrm{p} \leq 0.000$
The Table 3 shows the results of regression analysis between Internet addiction and Aggression. The results indicated that Internet Addiction is a significant predictor of Aggression. The predictor variable Internet Addiction $(\beta=.88)$ has a very high significant positive effect on outcome variable Aggression with the level of significance $\mathrm{p} \leq 0.000$. The adjusted $\mathrm{R}^{2}$ of .78 indicates that $78 \%$ variation in Aggression can be accounted due to Internet Addiction and $22 \%$ due to extraneous factors. The result supported hypothesis of this study.

Table 4: Inter-item Correlation of Internet Addiction Questionnaire $(\mathrm{N}=200)$

\begin{tabular}{clllllll}
$(\mathrm{N}=200)$ & \multicolumn{10}{l}{} \\
\hline 1 & .65 & 6 & .60 & 11 & .65 & 16 & .65 \\
2 & .63 & 7 & .55 & 12 & .60 & 17 & .58 \\
3 & .70 & 8 & .61 & 13 & .50 & 18 & .53 \\
4 & .58 & 9 & .58 & 14 & .63 & 19 & .57 \\
5 & .68 & 10 & .60 & 15 & .63 & 20 & .63 \\
\hline
\end{tabular}

$p<0.001$

Table 4 shows the inter item correlation of the items pertaining to Internet Addiction Questionnaire. The correlation values of all items of the Internet Addiction Questionnaire are significantly correlated to it at significance level $p<0.001$. This shows that the Questionnaire has high internal consistency.

Table 5: Inter-item Correlation of Physical Aggression ( $N=200)$

\begin{tabular}{llll}
\hline 1 & .74 & 6 & .66 \\
2 & .74 & 7 & .52 \\
3 & .68 & 8 & .66 \\
4 & .66 & 9 & .62 \\
\hline $\mathrm{p}<0.001$ & & &
\end{tabular}

Table 5 shows the inter item correlation of the items pertaining to subscale Physical Aggression. The correlation values of all items of the Physical Aggression are significantly correlated to it at significance level $p<0.001$. This shows that the subscale Physical Aggression has high internal consistency.

Table 6: Inter-item Correlation of Verbal Aggression $(\mathrm{N}=200)$

\begin{tabular}{ll}
\hline 10 & .65 \\
11 & .69 \\
12 & .68 \\
13 & .72 \\
14 & .67 \\
\hline$p<0.001$ &
\end{tabular}

Table 6 shows the inter item correlation of the items pertaining to subscale Verbal Aggression. The correlation of all items is significant with the subscale Verbal Aggression at the significance level $p<0.001$. This means that the subscale Verbal Aggression has high internal consistency.

Table 7: Inter-item Correlation of Anger $(\mathrm{N}=200)$

\begin{tabular}{ll}
\hline 15 & .62 \\
16 & .64 \\
17 & .60 \\
18 & .54 \\
19 & .58 \\
20 & .69 \\
21 & .71 \\
\hline $\mathrm{p}<0.001$ &
\end{tabular}

Table 7 shows the inter item correlation of the items pertaining to subscale Anger. The correlation of all items is significant with the subscale Anger at the significance level $p<0.001$. This shows that the subscale Anger has high internal consistency.

\begin{tabular}{cccc} 
Table 8: & Inter-item Correlation of Hostility $(\mathrm{N}=200)$ & \\
\hline 22 & .69 & 26 & .68 \\
23 & .71 & 27 & .72 \\
24 & .75 & 28 & .64 \\
25 & .73 & 29 & .71 \\
\hline $\mathrm{p}<0.001$ & &
\end{tabular}


Table 8 shows the inter item correlation of the items pertaining to subscale Hostility. The correlation values of all items of the Hostility are significantly correlated to it at significance level $p<0.001$. This shows that the internal consistency of subscale Hostility scale is high.

Table 9: $t$-Test Results for Comparing Male and Female Internet Addicts on Internet Addiction Questionnaire ( $N=200)$

\begin{tabular}{llllll}
\hline Groups & $\mathbf{N}$ & $\mathbf{M}$ & $\boldsymbol{\sigma}$ & $\mathbf{T}$ & $\mathbf{P}$ \\
\hline Male & 120 & 84.21 & 6.87 & 14.90 & 0.000 \\
Female & 80 & 57.50 & 15.17 & & \\
\hline df $=104.30$ & & &
\end{tabular}

$\mathrm{df}=104.30$

Table 9 shows that there is significant difference between the mean values of the male and female Internet users. Males are more internet addicts than females. Internet addiction is high among males than females.

Table 10: $t$-Test Results for Comparing Aggressive Male and Female on Buss-PerryAggression Scale $(\mathrm{N}=200)$

\begin{tabular}{llllll}
\hline Groups & $\mathbf{N}$ & $\mathbf{M}$ & $\mathbf{\sigma}$ & $\mathbf{T}$ & $\mathbf{P}$ \\
\hline Male & 120 & 119.13 & 9.79 & 13.02 & 0.000 \\
Female & 80 & 88.37 & 19.64 & & \\
\hline $\mathrm{df}=107.69$ & & & &
\end{tabular}

$\mathrm{df}=107.69$

Table 10 shows that there is significant difference between the mean values of aggression level of males and females. Males are more aggressive than females.

\section{Discussion}

The problem of internet addiction is very common in teenagers. The main purpose of this study was to explore the internet addiction among youngsters. The objectives of this study were to study the relationship between these two variables (internet addiction and aggression) and to study gender differences among internet addicts and aggressive people. The other objective of the study was to develop the psychometric properties of internet addiction questionnaire and Buss-Perry aggression scale in our culture.

To obtain these objectives, present research was conducted. Teen agers were contacted at different schools, colleges and different locations. After data collection the statistical analyses were done in the light of research objectives. The alpha co-efficient reliability in the present study determined was .90 for internet addiction and for Buss-Perry scale alpha co-efficient reliability was .94 which is highly significant thus it confirmed the applicability of the scales in Pakistani culture. The relationship between the variables was examined with the help of mean, standard deviation, t-Test and correlation and regression analyses.

Regarding the first hypothesis stated that there is positive relationship between Internet Addiction and Aggression. The Pearson correlation confirmed their inter correlation. The correlation between Internet Addiction Questionnaire and Buss-Perry Aggression scale was positive and significantly high, (.88**). Yoon and Park (2006) found that internet addiction is significantly correlated with aggression, selfesteem, impulsivity, parent's support and friend's support.

The results of second hypothesis "Internet addiction predicts Aggression positively" showed that Internet addiction $(\beta=.88)$ is significant predictor of Aggression. Second hypothesis is supported by the present data of study. This predicting role of the Internet Addiction to Aggression has been hypothesized mostly and been supported by different researches. According to Ko, Yen, Liu, Huang and Yen (2010) adolescents with internet addiction were more likely to have aggressive behaviors. Internet is a medium of communication full of healthy and unhealthy information, material, games, entertainment etc. Bendura (1961) had experimented the negative role of media (with reference to aggression) upon children. If the individual has exposure of aggressive media then the individual is more prone to increased aggression. People who play more violent video games they will be more prone to have aggressive feelings, actions and thoughts in simple words internet causes people to behave more aggressively (Ko, et al., 2009). The present study has again supported the positive correlation between internet addiction and aggression and internet addiction predicts aggression.

The results of third hypothesis "Males are more internet addicts than females" indicated that there is significant difference between the mean values of male and female internet users. Hypothesis 3 is supported by the present study. Hahn and Jerusalem (2001) also described that males used internet more than females. This means males have more chances to get exposure to internet due to their living style because they are anticipated to just concentrate on their studies and they are less engaged in household responsibilities as compare to females in Pakistan. They spend their free time using internet that is why they become more internet addicts than females.

The results of fourth hypothesis "Males are more aggressive than females" denoted that there is significant difference between mean values of males and female's level of aggression. The present study confirmed the gender differences. According to Ko, et al., (2005) and Wei (2007) males have more internet addiction they are more proviolent, they have more aggressive attitudes and less empathy than females. Basically males are more aggressive than females due to their differences in cognition, socialization and personality traits. In simple words males are more expressive and they have more chances to commit violence than females (Ashley, 2007). Violence is inherited in their biology because males have 20 times as much testosterone as females (Demause, 2010).

\section{Limitations of research}

Limitations of the study design, measurement and sampling caution one not to draw definitive conclusions and generalizations from the findings. The extraneous variables could not be controlled. This research also encounters certain limitations:

Data were collected only by the youngsters of Haripur city, thus the results could not be generalized to the teen agers of other cities as results may differ across the cities.

Sample size was limited.

The present study involves study of overall internet addiction and aggression problems. As internet addiction and aggression has many types so, those types should be studied individually in future to provide deeper understanding about this social issue.

\section{Conclusion}

Internet addiction and aggression are two major problems of teenagers' everyday life. This study was an effort to explore the relationship of these two variables and results of the study showed that internet addiction had significantly positive correlation with aggression.

\section{Recommendations for future research}

The research provided valuable information in cultural context of Pakistan. It had identified further suggestions which a future research can accommodate. Few recommendations could be useful to improve the future studies like;

Larger sample size should be taken in future researches.

The present study sample was taken from Haripur city only. The study should be extended to other cities of Pakistan. More research should be conducted in different areas of country so; the proper presentation of population can provide better understanding of these emerging issues in society.

Translated version of these questionnaires should be used in our country so then people can understand them in easy way.

As adolescence (teen age) is a period in which a lot of changes together with social affiliation, interaction with peers, and physical changes etc., normally occurs which affects the overall performance of the people. In future studies it is therefore suggested that these factors should be incorporated for developing an in-depth understanding of the factors involved in aggressive conduct of the youngsters. 
Different age levels should be considered for the variables in future studies.

Researchers should study different other psychological problems associated with internet addiction and aggression.

Sample for the present study was taken from educational institutes only the study should be extended to other work and social settings.

\section{References}

Ashley, B. (2007). Why males are more aggressive than females. Retrieved October 6, 2012 from http://voices.yahoo.com/why-males-moreaggressive-than-females-559104.html?cat $=72$

Ali, M. (2008). Impact of parental attachment on aggressive behavior of adolescents. Un published MSc. Dissertation, National Institute of Psychology, Quaid e Azam university, Islamabad.

Alavi, S. S., Alaghemandan, H., Maracy, M. R., Jannatifard, F., Eslami, M. \& Ferdosi, M. (2010). Impact of addiction to internet on a number of psychiatric symptoms in students of Isfahan universities, Iran, 2010. Retrieved October 5, 2012 from http://www.sid.ir /en/VEWSSID/J pdf/127320120209.pdf

Alavi, S. S., Maracy, M. R., Jannatifard, F., \& Eslami, M. (2011). The effect of Psychiatric symptoms on the internet addiction disorder in Isfahan's university students. Retrieved October 5, 2012 from http://www. ncbi.nlm. nih.gov/pmc/articles/PMC3214398/

Anderson, C. A., \& Bushman, B. J. (2002). Human aggression. Retrieved October 6, 2012 from www.psychology.iastate.edu/faculty/caa/abstracts/2000.../02ab.pdf

Bandura, A. (1961). Bobo doll experiment. Retrieved October 6, 2012 from http://explorable.Com/bobo-doll-experiment.html\#ixzz1 wpdqnYLm

Berkowitz, L. (1968). Impulse, aggression and the gun. Psychology today, pp.18-22. (p.358). Retrieved October 11, 2012 from http://rint.rechten.rug.nl/rth/dennen/problem3.htm

Barkoviak, M. (2009). Teen internet addiction linked to ADHD, Aggression. Retrieved October 7, 2012 from http://www.addictioninfo.org/ articles/3830/1/Teen-Internet-

Buss, A. H., \& Perry, M. (1992). The aggression questionnaire. J. Pers. Soc. Psychol. 63: 452- 459, 1992. Retrieved October 12, 2012 from pmbcii.psy.cmu.edu/core.../Buss_Perry_Aggression_Questionnaire.p...

Chou, C., Condron, L., \& Belland, J. C. (2005).A review of the research on internet addiction. Retrieved October 15, 2012 from www.acrwebsite.org/volumes/v36/NAACR_v36_94.pdf

Chiu, S. I., Lee, J. Z., \& Huang, D. H. (2004). Cyber psychology \&behavior.7 (5): 571-581. doi: 10.1089/cpb.2004.7.571. Retrieved October 14, 2012 from liebertpub.com/doi/abs/10.1089/cpb.2004.7.571? journalCode $=\mathrm{cpb}$

Demause, L. (2010). Why males are more violent. The Journal of Psychohistory140 Riverside Drive, Suite 14H, New York, NY 10024 (212) 799-2294. Retrieved October 16, 2012 from http://www.psychohistory.com/originsofwar/02_whymalesaremoreviolent. html

Erikson, E. (1950). Erikson's psychosocial development theory. Retrieved October 5, 2012 from http://www.businessballs.com/erik_erikson_psychosocial_theory.htm

Esen, B. K., \& Gundogdu, M. (2010).The relationship between internet addiction, peer pressure and perceived social support among adolescents. Retrieved

October 18, 2012 from http://www.eab.org.tr/public/ijer/1/2/4_esen.b.k.pdf

Feng, E. Z., Ho, H. C., \& Song, Y. J. (2011). Effects of an online rational emotive curriculum on primary school student's tendencies for online and real world

aggression. Retrieved October 18, 2012 from http://www.eric.ed. gov/

ERICWebPortal/search/detailmini.jsp

Frangos, C. C., Frangos, C. C., \& Sotiropoulos, I. (2011). Problematic interne use in Chinese adolescents and its relation to psychosomatic symptoms and life Satisfaction. Retrieved October 19, 2012 from http://www.ncbi.nlm.nih.gov/

Hayes, N. (1994). Principles of comparative psychology. East Sussex: Lawrence Erlbaum Association Ltd.

Geen, R. G., \& Donnerstein, E. I. (1998). Human aggression: Theories, research, and implications for social policy. Retrieved October 21, 2012 from

http//definedaggressionasaresponsethatdeliversnoxiousstimulitootherorgan isms.\&source $=$ Du2nAZdXBK\&sig

Hahn \& Jerusalem. (2001). An analysis of internet addiction levels of individuals according to various variables. Retrieved October 22, 2012 from www.tojet.net/articles/v10i4/1047.pdf

Jenaro, C., Flores, N., Gomez-Vela, M., \& Caballo, C. (2007). The effect of psychiatric symptoms on the internet addiction disorder in Isfahan's
University students. Retrieved October 24, 2012 from http://www.ncbi.nlm.nih.gov/pmc/articles/PMC3214398/

Kandell, J. J. (1998). Internet addiction on campus: the vulnerability of college students. Retrieved October 25, 2012 from http://www.deepdyve.com/lp/mary-ann-liebert/internet-addiction-oncampus-the-vulnerability-of-college-students-tc1LjkFXYZ

Ko, C. H., Yen, Y. J., Chen, C. C., Chen, S. H., \& Yen, C. F. (2005). Genderdifferences and related factors affecting online gaming addiction among Taiwanese adolescents. Journal of Nervous and Mental Disease, 193(4), 273-277. Retrieved October 26, 2012 from http://ses.library.usyd.edu.au/bitstream/2123/8564/2/Consequences.pdf

Ko, C. H., Liu, G. C., Hsiao, S., Yen, J. Y., Yang, M. J., Lin, W. C., Yen, C. F., \& Chen, C. S. (2009). Brain activities associated with gaming urge of online gaming addiction. Journal of Psychiatric Research, 43(7), 739-747.

Ko, C. H., Yen, C. F., \& Yen, J. Y. (2010). Internet addiction: on going research in Asia. Retrieved October 26, 2012 from http:/www.ncbi. nlm.nih.gov/pmc/articles/PMC2911088/

Ko, C. H., Liu, G. C., Hsiao, S., Yen, J. Y., Yang, M. J., Lin, W. C., Yen, C. F., \& Chen, C. S. (2009). Brain activities associated with gaming urge of online gaming addiction. Journal of Psychiatric Research, 43(7), 739-747.

Ko, C. H., Yen, Y. J., Chen, C. C., Chen, S. H., \& Yen, C. F., (2005) and Wei, (2007). Consequences of Play: A systematic review of theeffects of online gaming.International Journal of Mental Health and Addiction, 10(1), 3-23. Retrieved October 26, 2012 from http://ses.library.usyd.edu.au/bitstream/2123/8564/2/Consequences $\% 20$ of $\% 20$ Play $\% 20$ A $\% 20$ Systematic\%20Review\%20of\%20th20Effects

Kim, Y., Park, J. Y., Kim, S. B., Jung, I. K., Lim, Y. S., \& Kim, J. H. (2010). Problematic internet use in Chinese adolescents and its relation to psychosomatic symptoms and life satisfaction. Retrieved October 25, 2012 from http://www.ncbi.nlm. nih.gov/pmc/articles/PMC3214169/

Lin \& Tsai. (1999). A review of the research on internet addiction. Retrieved October27, 2012 from li123-4.members.linode.com/.../..

Lucy, O. (2011). What psychosocial factors influence Internet use of Internet addictedteenagers in baybay, leyte. Retrieved October 27, 2012 from http://devcompage.com/?p=3459

Liu, C. Y., \& Kuo, F. Y. (2007). A study of internet addiction through the lens of the interpersona theory. Retrieved October 27, 2012 from http://www.ncbi.nlm.nih.gov/pubmed/18085967

Mattson, M. P., (2003). Neurobiology of aggression: understanding and preventing violence. New Jersey, Human press.

Morahan, Martin, \& Schumacker. (2000). A review of the research on internet addiction. Retrieved October 28, 2012 from li1234.members.linode.com/.../...

Munteanu, Anca; Costea, Iuliana; Palos, Ramona; Jinaru, \& Adrian. (2009). Psychological and behavior aspects regarding internet addiction. Retrieved October 28, 2012 from http://connection.ebscohost.com/c/articles/47081232/psychologicalbehavior- aspects-regarding-internet-addiction.

Mehroof, M., \& Griffiths, M. D. (2010). Online gaming addiction: The role of Sensation Seeking, self-control, neuroticism, aggression, state anxiety, and trait anxiety. Retrieved October 27, 2012 from http://online.liebertpub.com/doi/abs/10.1089/cyber.2009.0229

Orpinas, P. (2001). The aggression scale: A self-report measure of aggressive behavior for young adolescents. Retrieved October 28, 2012 from www.publichealth .uga.edu/hpb/sites/.../2001-Aggression\%20Scale.pd...

Regina, M., Jennifer, Hechanova, \& Czincz. (2008). Internet addiction in Asia: reality or myth? Retrieved October 28, 2012 from www.idrc.ca/uploads/user- S/12531993781 rad 4E1AD.DOC

Rajani, M. K. \& Chandio, M. S. (2004). Use of internet and its effects on our society.Retrieved October 28, 2012 from szabist.pk/.../Session\%20VIII\%20Paper\%20No\%202\%20(P\%20157-.

Sahin, C. (2011). An analysis of internet addiction levels of individuals according to various variables. Retrieved October 28, 2012 from www.tojet.net/articles

Scherer. (1997). A review of the research on internet addiction. Retrieved October 28,2012 from li123-4.members.linode.com/.../..

Takahira, M., Ando, R. \& Sakamoto, A. (2008). Effect of internet use on depression, loneliness, aggression and preference for internet communication: a panel study with 10- to 12-year-old children in Japan. Retrieved October 30, 2012 from http://dl.acm.org/citation.cfm?id=1387208

Tumanov, S. (2011). Internet addiction: metasintez impiricheskih research 1996-2006 years. Retrieved October 30, 2012 from http://cyberpsy.ru/2011/01/internet-addikciya-etasintez-

Widyanto, L., \& Mcmurran, M. (2004). The psychometric properties of the internet addiction test. Retrieved October 30, 2012 from https://docs.google.com/viewer?a=v\&q=cache:Ns_1J7ZHxtAJ:www.netad 
diction.com/articles/InternetAddictionTestResearch.impiri/ /v10i4/1047.pdf

Young, K. S., \& Rodgers, R. C. (1998). The relationship between depression and internet addiction. Retrieved October 31, 2012 from http://netaddiction.fusionxhost.com/articles/cyberpsychology.pdf

Young. (1998). A review of the research on internet addiction. Retrieved October $31, \quad 2012$ from li1234.members.linode.com/.../...pmc/articles/PMC3214169/

Yang. (2005). Problematic internet use in high school students in Guangdong province, China. Retrieved October 30, 2012 from http://
www.plosone.org/article/info\%3Adoi\%2F10.1371\%2Fjournal.pone.00196 60\#pone.0019660-Yang1

Young, K. (1996, 1998). The psychometric properties of the internet addiction test.Retrieved October $\quad 31, \quad 2012$ www.netaddiction.com/articles/InternetAddictionTestResearch.pdf

Yoon, Y. M. \& Park, H. M. (2006). Personal and environmental predictors of internet addiction in higher grade elementary school students. Retrieved October $\quad 31$, 2012

http://koreamed.org/SearchBasic.php?RID=1095KJCHN\%2F2006. 